\title{
OS CURRÍCULOS DE LICENCIATURA EM LÍNGUA INGLESA: Formação para o trabalho com crianças
}

\author{
Andrea Cristina Gomes Monteiro ${ }^{1}$ \\ Marcia Regina Selpa Heinzle ${ }^{2}$
}

\section{INTRODUÇÃO}

O ensino de Língua Estrangeira (LE) historicamente apresenta-se, de forma facultativa nas instituições de ensino no Brasil, dependendo de acordos políticos e mercadológicos estabelecidos entre países ou inicialmente entre as cortes. A sua primeira aparição no cenário nacional remonta o século XVIII quando o Brasil sofre influência inglesa principalmente no que concerne ao comércio (LIMA; QUEVEDO-CAMARGO, 2008).

No passado, a inclusão de línguas estrangeiras geralmente acontecia de maneira lenta e sutil, atendendo a necessidades político-econômico-ideológicas e envolvendo pequena parcela da população, compreendida pela classe social alta que via no domínio de outra(s) língua(s) maior prestígio (SANTOS, 2005, p. 47).

Com a elaboração da LDB (Lei de Diretrizes e Bases) de $1961^{3}$, inclui-se o ensino de uma LE nas escolas básicas. Esta, aprimorada na LDB de $1996^{4}$, assegura a Língua Inglesa (LI) como obrigatória nos anos finais do Ensino Fundamental. Almeida Filho (2003) aponta para o fato de que a profissão do professor enquanto mestre de línguas estrangeiras no Brasil somente foi regularizada no último século, o que dificultou ainda mais o acesso às línguas estrangeiras. Contudo, ainda se faz incerto o rumo do ensino da LI para as crianças, embora saiba-se da sua existência em diversos espaços, tais como: escolas particulares, escolas de idiomas e em algumas escolas públicas.

Segundo Rocha (2006), as propostas de formação de professores habilitados para o ensino de LI para crianças ainda acontece de modo isolado, pois não existem leis que definam a

\footnotetext{
${ }^{1}$ Mestre pelo Programa de Pós Graduação em Educação pela Universidade Regional de Blumenau (FURB), integrante do Grupo de Estudos e Pesquisas sobre Ensino Superior (GEPES-FURB) e graduada em Letras com habilitação em Português e Inglês (UNIVILLE). Atualmente, é Professora de Inglês do Instituto Federal Catarinense - Campus Camboriú (IFC). E-mail: jve3043@gmail.com.

${ }^{2}$ Doutora em Educação pela Universidade Estadual de Campinas (UNICAMP). Atualmente é Professora e pesquisadora da Universidade Regional de Blumenau (FURB) no Programa de Pós Graduação em Educação. É coordenadora do Grupo de Estudos e Pesquisas sobre Ensino Superior (GEPES-FURB). E-mail: selpamarcia@gmail.com.

${ }^{3}$ UNIVERSIDADE DE BRASÍLIA, 2016, n.p

${ }^{4}$ UNIVERSIDADE DE BRASÍLIA, 2016, n.p
} 
obrigatoriedade dessa oferta em escolas regulares, diferentemente de países europeus. Isso implica na ausência de uma formação que garanta a preparação de profissionais que trabalhem com o ensino de inglês para crianças, tendo em vista que cada temporalidade tem a sua própria forma de aquisição da língua, bem como metodologias que se tornam mais adequadas a elas (SPADA, 2004). Essa falta de formação específica contribui para que, conforme Santos (2005), não existam parâmetros de avaliação para o desempenho profissional do professor de LI que ministre aulas para crianças.

Diante do exposto, vale destacar que a formação inicial ${ }^{5}$ de professores de LI deve conter pelo menos os subsídios básicos para a sua atuação inicial nas escolas, sejam elas com oferta de Ensino Fundamental (anos iniciais e finais), Ensino Médio, Educação de Jovens e Adultos e/ou cursos de idiomas. Esse profissional poderá, por meio de formação continuada, galgar novos conceitos e patamares em sua formação, adequando-se às suas necessidades mais específicas.

Contudo, reflete-se o fato de que crianças possuem processos de aprendizagem diferentes de adolescentes, jovens e adultos. Além disso, as metodologias desenvolvidas para o ensino de uma LE para crianças diferem das que são utilizadas para outras faixas etárias (SANTOS; BENEDETTI, 2009, p. 337) ou mesmo para a aquisição da Língua Portuguesa (LP).

Em consequência disso, surge a preocupação com a formação oferecida pelas universidades para estes profissionais que se tornarão professores de inglês para crianças. Essa preocupação com a formação dos professores que atuam no ensino de crianças corrobora as ideias de Santos (2005), Santos e Benedetti (2008), Santos e Zeggio (2002), Rocha (2006), entre outros. Diante dessa discussão, o objetivo deste artigo é identificar nas propostas curriculares dos cursos de Letras com habilitação em LI de Santa Catarina, a intencionalidade de uma formação docente para o trabalho com crianças. Nesse sentido, realizou-se uma pesquisa documental (PIMENTEL, 2001) a partir dos dados contidos nas plataformas das universidades que ofertam o curso de licenciatura em Letras (Inglês). Tais documentos descrevem os componentes curriculares a serem cursados pelos acadêmicos, e seus respectivos ementários.

De modo a apresentar as questões sobre a formação inicial desses profissionais, este artigo está dividido em quatro partes: impressões iniciais dos documentos e websites dos cursos analisados; descrição dos dados, incluindo a análise das matrizes e ementários de cada curso, identificando termos relacionados diretamente com a infância (infância, criança(s), infantojuvenil,

\footnotetext{
5 "Por formação inicial compreendemos a instância primeira de formação no nível universitário para o exercício da profissão, na qual se certifica a preparação do professor como profissional." (RAMALHO, NUÑEZ, GAUTHIER, 2004, p.97).
} 
infantil, anos iniciais e educação infantil) ou que podem ter correlação como tema infância (desenvolvimento, aquisição da linguagem, alfabetização e Ensino Fundamental); categorização dos termos elencados na seção anterior, pensando em seu enfoque pedagógico ou para as especificidades da infância; e a última seção do artigo aborda as considerações a respeito das análises realizadas.

\section{IDENTIFICAÇÃO DOS CURSOS DE LETRAS EM SANTA CATARINA}

Em pesquisa com o descritor "curso de Letras presencial em Santa Catarina" e "curso de Letras em Santa Catarina" no site google, obteve-se uma lista de Instituições de Ensino Superior (IES) que possuem o curso de Letras. De acordo com os descritores mencionados, obteve-se as seguintes instituições: FURB (Universidade Regional de Blumenau), UFSC (Universidade Federal de Santa Catarina), UNISUL (Universidade do Sul de Santa Catarina), UNIPLAC (Universidade do Planalto Catarinense), UNIVALI (Universidade do Vale do Itajaí) e UNIVILLE (Universidade da Região de Joinville). Contudo, como foram poucos os resultados obtidos, acrescentou-se mais um descritor na ferramenta de busca: universidades de Santa Catarina. Com este último, encontrou-se uma lista de universidades e faculdades ${ }^{6}$ no Estado com todos os cursos existentes. A partir desta lista, foi possível encontrar mais cursos de Letras: UFFS (Universidade Federal da Fronteira Sul), UNESC (Universidade do Extremo Sul Catarinense), UNOESC (Universidade do Oeste de Santa Catarina), UNC (Universidade do Contestado), UNIARP (Universidade do Alto Vale do Rio do Peixe) e UNOCHAPECÓ (Universidade Comunitária de Região de Chapecó).

Dentre as 77 IES encontradas, 12 delas ofertam o curso de licenciatura em Letras na modalidade presencial. Entretanto, na UFFS, somente há a oferta das habilitações em Língua Portuguesa e Língua Espanhola. Na UNESC, UNISUL, UNIVALI e UNOESC, há somente a oferta da habilitação em Língua Portuguesa. Esses fatores inviabilizam a pesquisa dessas universidades.

As outras sete IES que ofertam o curso de Letras e que contemplam a habilitação em LI são: FURB, UFSC, UNC, UNIARP, UNIPLAC, UNIVILLE e UNOCHAPECÓ. A partir deste momento, os cursos dessas Instituições de Ensino Superior serão nomeadas por letras para preservar a identidade das mesmas.

Os dados obtidos para esta pesquisa foram extraídos dos websites dos cursos de Letras das universidades acima citadas, conforme quadro abaixo:

\section{QUADRO 1. FONTE DOS DADOS E HABILITAÇÕES DOS CURSOS}

\footnotetext{
${ }^{6}$ Lista disponível no site: http://www.altillo.com/pt/universidades/brasil/estado/santacata.asp
} 


\begin{tabular}{|l|l|l|}
\hline CURSO DE LETRAS & FONTE DOS DADOS & HABILITAÇÕES \\
\hline A & Matriz, ementário e planos de ensino & Inglês \\
\hline B & Matriz e ementário & Português/Inglês \\
\hline C & Matriz e ementário & Português/Inglês \\
\hline D & Matriz e ementário & Português/Inglês/Espanhol \\
\hline E & Matriz & Português/Inglês \\
\hline F & Projeto Pedagógico de Curso (PPC) & Português/Inglês \\
\hline G & Ementário & Português/Inglês \\
\hline
\end{tabular}

Fonte: pesquisadoras.

Quando analisados as matrizes, os ementários, e o Projeto Pedagógico de Curso (PPC) dos cursos, percebe-se uma diferença significativa da quantidade de disciplinas destinadas à habilitação do profissional de LP, quando em comparação com as disciplinas destinadas à formação de professores de LI. Esse fato reafirma a preocupação apontada por Gatti e Barreto (2009) quanto à real formação para futuros professores de línguas. As autoras supracitadas identificam que um curso com duas ou mais ênfases pode priorizar apenas uma das ênfases, o que o presente estudo busca retratar na tabela 1 .

TABELA 1. NÚMERO DE COMPONENTES CURRICULARES DESTINADO A CADA LÍNGUA

\begin{tabular}{l|l|l|l|l|l|l|l}
\hline CURRÍCULO & A & B & C & D & E & F & G \\
\hline Disciplinas voltadas para Português & 0 & 17 & 19 & 20 & 17 & 18 & 21 \\
\hline Disciplinas voltadas para Inglês & 40 & 8 & 10 & 10 & 10 & 14 & 14 \\
\hline Disciplinas voltadas para Espanhol & 0 & 0 & 0 & 10 & 0 & 0 & 0 \\
\hline
\end{tabular}

Fonte: pesquisadoras.

Embora a carga horária mínima exigida em resoluções ${ }^{7}$ seja cumprida em cada um dos cursos ofertados pelas IES, o que prende a atenção, antes de tudo, é o fato de que esses futuros egressos poderão atuar como professores de LI, mesmo quando o currículo não enfatize disciplinas voltadas para a habilitação em LI

Entende-se que a licenciatura, como área do ensino superior, deve propiciar o domínio dos conhecimentos histórica e socialmente construídos em determinadas áreas do saber, ou seja, sólida formação teórica; deve capacitar os estudantes nas competências e habilidades que proporcionem condições necessárias de ensino e aprendizagem [...]. (SANTOS; ZÉGGIO, 2002, p.160)

Como afirmam os autores acima citados, faz-se importante que os futuros professores recebam, por meio dos cursos de licenciatura, uma formação que acarretará em uma atuação de

\footnotetext{
${ }^{7}$ Resolução CNE/CP n ${ }^{\circ}$ 1, de 18 de março de 2011 e Resolução CNE/CP nº2, de 19 de fevereiro de 2002.
} 
qualidade e reflexiva. Sem uma preparação mínima para todos os campos de atuação os quais o curso pretende formar, esses profissionais podem se sentir desamparados quando enfrentarem os desafios da sala de aula (TARDIF, 2012).

Tendo em vista a análise dos currículos dos cursos que ofertam a habilitação em LI, na sequência, são realizadas considerações e análises de modo individual.

\section{Currículo $A$}

Na página inicial do curso de Letras, com habilitação em LI do currículo A, há a descrição das características do curso e das possiblidades de campo de atuação para o profissional formado: escolas públicas e privadas que ofertam o Ensino Fundamental, além dos cursos de idiomas. Outras possibilidades de atuação, descritas na página do curso, estão em tradução e revisão de textos.

Pensa-se que essas possibilidades de atuação podem colocar os professores frente ao ensino de crianças de diferentes faixas etárias, desde as crianças ainda não alfabetizadas, assim como as que já foram alfabetizadas. Portanto, é importante perceber se, ao longo do curso de Letras, os acadêmicos têm acesso a disciplinas que abordem o ensino de inglês às crianças.

Este é o currículo que mais apresenta disciplinas voltadas para o ensino de LI, por ser o único curso superior que oferta a habilitação somente na língua alvo. Nele, pode-se observar a presença de duas disciplinas voltadas à formação do futuro docente que atuará no ensino de crianças. São elas: Estudos linguísticos II e Psicologia Educacional: desenvolvimento e aprendizagem.

$\mathrm{Na}$ primeira disciplina, existe no ementário, os tópicos: 'etapas do desenvolvimento infantil', 'modelos de aquisição da linguagem' e 'diferentes pressupostos teórico-epistemológicos da aquisição da escrita' que apontam informações referentes ao ensino de LI para crianças. Por se tratarem de estudos ligados à aquisição da escrita, entende-se que estejam voltados também para a formação para o trabalho com a infância.

Na segunda disciplina, encontra-se o termo 'infância' na ementa (Introdução ao estudo de desenvolvimento e de aprendizagem - infância, adolescência, idade adulta) e também em várias das referências como: Campos-de-Carvalho; Souza (2005), Cole; Cole (2003), Elali (2003), Faria (2000), Sodré (2005) e Sylva (1994). Todas essas obras (ver tabela 2) trazem em seus títulos os termos criança, infância, educação infantil ou creches, o que indica que há a possibilidade de se desenrolarem discussões sobre a infância ao longo da disciplina. 
Outras disciplinas que podem apresentar discussões acerca da infância, mas que não apresentam termos ligados diretamente à infância são: Didática, Ensino e aprendizagem de LI, Ensino e aprendizagem de LE, Introdução à linguística aplicada e, Linguística aplicada I e II. Tais disciplinas foram elencadas por se tratarem de teorias e discussões acerca da aquisição da língua e também pelo estudo de metodologias/abordagens que podem ser desenvolvidas em sala de aula. Dessa forma, entende-se que existe a possibilidade de haver discussões voltadas ao uso de metodologias adequadas para o ensino de LI para crianças ou mesmo formas como crianças adquirem uma LE.

\section{Currículo B}

Encontramos sinalizações da formação ofertada pelo currículo B na página inicial do curso de Letras com dupla habilitação (Português/Inglês), na qual descreve o campo de trabalho que o futuro profissional poderá atuar: ensino em escolas públicas e particulares (Ensino Médio e Ensino Fundamental), assessoria linguística, tradução e revisão de textos.

Sobre o currículo B, destaca-se a presença da frase 'Inserção no cotidiano escolar da Educação Básica' em praticamente todas as ementas do curso. Se analisarmos somente esta frase do ementário, poderíamos interpretar que a discussão sobre a infância e a adolescência está implicitamente contemplada nas disciplinas, posto que, com a inserção que o acadêmico fará ao observar a educação básica, entrará em contato com situações envolvendo crianças e adolescentes. Entretanto, não se pode afirmar com segurança que existam discussões acerca do tema infância, a partir da inserção dos licenciandos na escola, tendo em vista que não há a descrição de como ocorre a 'inserção do acadêmico’ nas escolas de educação básica.

$\mathrm{Na}$ proposta curricular, foram encontradas quatro disciplinas que apresentam termos que correspondam ao ensino para crianças, sendo que uma dessas ocorrências se deu em uma das disciplinas específicas da formação em LI, como é o caso da disciplina 'Metodologia do ensino de Língua Inglesa para séries iniciais'.

A segunda disciplina, com palavras que diretamente citam o termo criança, foi a 'Neurociência', sendo que em sua ementa traz o termo 'desenvolvimento da criança'. Já a disciplina 'O lúdico como processo de aprendizagem' apresenta em sua ementa o termo 'formação da criança'. Portanto, as disciplinas possivelmente contemplarão discussões sobre a formação da criança, além do uso de ludicidade como forma de ensino.

A última disciplina a apresentar diretamente termos ligados à infância foi 'Atividade física como qualidade de vida na infância e adolescência'. Nela, toda a ementa e todos os objetivos 
apresentam os termos criança, crianças ou infância. Com isso, existe a possibilidade de haver discussões sobre o desenvolvimento da criança ao longo da formação inicial.

Além dessas disciplinas, foram elencadas outras disciplinas que poderiam abordar conceitos relacionados a discussões sobre a infância. São elas: Currículo e didática, Psicologia da educação, Políticas públicas, História e legislação de Ensino, Estágio curricular supervisionado de Língua inglesa I e IV, Oficina de produção de materiais, Modelagem matemática e, Língua Inglesa VIII. Em tais disciplinas, há a referência ao Ensino Fundamental ou níveis de ensino, LDB de 1996, Metodologias, Fases do desenvolvimento ou Processos de aprendizagem.

\section{Currículo C}

Em relação à análise desse curso de Letras destaca-se a oferta da habilitação em LP e LI. Na página de apresentação do curso na internet, descrevem-se como campo de trabalho as escolas das redes públicas e privadas de ensino, os cursos de línguas, a revisão de textos e as escolas preparatórias para concursos públicos. Por se tratar do trabalho nas escolas de idiomas e redes públicas e privadas, o profissional de Letras também precisa estar apto para o trabalho com uma variedade de faixas etárias, incluindo a infância.

O currículo C do curso de Letras dispõe de três disciplinas que apresentam termos voltados também à formação para o trabalho com a infância: Literatura infantojuvenil, Seminário de prática em Letras I e Metodologia do ensino da LP. Todavia, nenhuma dessas disciplinas está voltada para a formação do professor de LI, posto que todas pertencem às disciplinas de formação em LP.

A primeira disciplina citada coloca o termo infantojuvenil em sua ementa, bem como relaciona obras voltadas para a infância em suas referências, como: Albergaria (1997), Coelho (1991), Foucambert (1998), Lajolo e Zilbermann (1984), Perroti (1986), Áries (1981), Coelho (1991), Zilberman e Magalhães (1984), e Zilberman (1982). Todas essas obras (ver tabela 2) apresentam os termos literatura infantil, criança ou infantojuvenil em seus títulos.

A segunda disciplina complementa a primeira, pois é composta por apresentações e discussões dos temas abordados nas aulas de literatura infantojuvenil. Dessa maneira, as referências utilizadas e os termos destacados são os mesmos apresentados pela primeira disciplina.

A terceira disciplina contém o termo 'criança' na obra de Curto (2000). Além dessa obra que apresenta diretamente um termo ligado à infância, ainda pode-se perceber, nas referências da disciplina, o termo alfabetização, que remonta a discussões sobre o processo de aquisição da língua por uma criança nas obras de Cagliari (1989), Citelli (2001), Cócco (1996) e Faraco (2000). 
Além dessas três disciplinas, outras seis apresentam termos que podem possibilitar discussões voltadas para o ensino de crianças. São elas: Linguística II e III, Estrutura e funcionamento do ensino, Didática geral, Metodologia do ensino da Língua Inglesa e Estágio supervisionado de Língua Inglesa. Essas disciplinas apresentam os termos: alfabetização, LDB de 1996, proposta curricular ou ensino da LI. Todos esses termos podem estar relacionados a alguma discussão sobre o funcionamento do Ensino Fundamental, legislação e orientações que regem o Ensino Fundamental que por consequência envolvem o ensino de crianças.

\section{Currículo D}

Este curso de Letras propõe três habilitações (português, inglês e espanhol). Em sua página inicial, destaca-se a possibilidade de atuação do profissional formado, como professor em escolas públicas e particulares de Ensino Fundamental e Médio, bem como em escolas de línguas, além de poder tornar-se intérprete, redator, revisor de textos, secretário e assessor de comunicação.

O currículo D oferece três disciplinas que apresentam termos ligados à infância ou em seu ementário ou em suas referências. As ementas e referências bibliográficas do currículo desse curso são praticamente idênticas às do currículo C. A diferença reside nas disciplinas de cunho específico para a Língua Espanhola. Portanto, aqui somente será abordada a disciplina que difere do currículo C.

Dessa forma, a disciplina em Língua Espanhola que pode oferecer discussões sobre a infância é Estágio supervisionado de Língua Espanhola. Os termos encontrados, nesse componente curricular os quais considera-se que podem abordar discussões e estudos acerca da infância são: princípios didático-pedagógicos em Língua Espanhola, e o próprio Ensino Fundamental.

\section{Currículo $E$}

Este curso de Letras também possui uma formação com dupla habilitação: Português/Inglês. Contudo, na página do curso, não está disponível o ementário, ou PPC, somente a matriz curricular vigente. Logo, para a análise desse curso, não se pode afirmar que exista a presença de termos referentes à infância nos documentos disponíveis ao público que estão na internet, com exceção da disciplina de Literatura infantil-juvenil. O que se pode afirmar, por sua vez, é uma possibilidade de discussões acerca do tema nas disciplinas de:

Linguística aplicada à língua estrangeira -aborda a aquisição de uma LE;

Psicologia da educação - debate de processos psicológicos que envolvem a aprendizagem;

Didática - abordagem de temas envolvendo as formas de trabalho em sala de aula; 
Metodologia do ensino de LI -metodologias que podem ser utilizadas no ensino de inglês;

Políticas públicas e gestão escolar -aspectos da legislação, como a LDB de 1996 e as propostas curriculares que contemplam a infância na Educação Infantil e Ensino Fundamental.

Esse curso habilita o futuro profissional para atuar no Ensino Fundamental e Médio, bem como em institutos de idiomas, além de habilitar para o trabalho como revisor. Contudo, de acordo com o material exposto no site do curso de Letras desta instituição, ainda são poucas as disciplinas voltadas para a formação em LI que podem oferecer discussões acerca da infância, objetivando preparar esses profissionais para o possível trabalho em escolas de idiomas e anos iniciais do Ensino Fundamental.

\section{Currículo $F$}

$\checkmark$ A página destinada ao curso de Letras do currículo F apresenta que o curso atua na formação da dupla habilitação (Português/Inglês). Essa página disponibiliza somente a matriz curricular do curso vigente e o PPC na versão resumida sem a descrição dos ementários.

$\checkmark$ O campo de atuação apresentado no site abrange desde a docência no ensino regular e extracurricular, revisão e tradução de textos, além da possível atuação como intérprete. Assim, tanto para a atuação como docente quanto para a atuação nos outros campos de trabalho, o profissional formado precisará ter conhecimento profundo de português e inglês, somado ao fato de que para a sua atuação como docente ainda precisará de uma formação voltada para discussões pedagógicas no que se refere ao ensino de crianças com as quais esse profissional possa vir a atuar.

$\checkmark$ Nesse curso, existe uma possível discussão sobre a infância em quatro disciplinas voltadas para a formação em LI:

$\checkmark$ Metodologias do ensino de línguas: metodologias a serem desenvolvidas em sala de aula com crianças, adolescentes, jovens e adultos;

$\checkmark$ Linguística aplicada: discussões acerca da aquisição de uma LE, ou seja, a aquisição desta por crianças;

$\checkmark$ Estágio I e II - Língua Inglesa: debate das dificuldades e enfrentamentos que acontecem em sala de aula, inclusive em aulas destinadas ao Ensino Fundamental, ou seja, para crianças. 
$\checkmark$ Além das disciplinas apresentadas acima, existe a possibilidade de haver discussões sobre a infância em disciplinas de cunho geral, ou seja, que não estão voltas para a formação especificamente de nenhuma das habilitações (Português/Inglês). São elas:

$\checkmark$ Didática geral: abordagem de temas envolvendo as formas de trabalho em sala de aula;

$\checkmark$ Psicologia da educação: debate de processos psicológicos que envolvem a aprendizagem;

$\checkmark$ Políticas e gestão de educação básica: abordagem de aspectos da legislação, como a LDB de 1996 e as propostas curriculares que contemplam a infância na Educação Infantil e Ensino Fundamental.

Para além dessas disciplinas, a disciplina de 'Literatura infantil e juvenil brasileira' é a única disciplina que apresenta o termo ligado à infância em sua nomenclatura, o que demonstra a intenção de realizar discussões acerca do tema 'infância'.

\section{Currículo G}

Na página disponível na internet sobre o curso de Letras com habilitação em Português e Inglês ofertado, é apresentado o perfil do profissional a ser formado e o seu campo de atuação. Dentre as possibilidades de trabalho, estão a perspectiva de se tornar docente em escolas públicas e privadas para os anos finais do Ensino Fundamental e o Ensino Médio, além da alternativa de se tornar tradutor, intérprete, revisor de textos e até mesmo pesquisador.

Considera-se, diante do exposto, que o campo de atuação proposto pelo currículo G, não tem como foco a formação do profissional para o trabalho com os anos iniciais ou com o curso extracurricular de línguas. Nesse sentido, o currículo que forma esses profissionais não precisaria contemplar nenhum aspecto relacionado à infância.

Contudo, destaca-se que no histórico dos licenciados não existe nenhuma restrição quanto ao campo de trabalho no que consta à atuação com os anos iniciais ou educação infantil. Portanto, a certificação não impedirá a atuação dos professores frente ao público de crianças em cursos de idiomas ou mesmo na educação infantil, e anos iniciais de escolas particulares/públicas.

Visto sob essa perspectiva, nesse curso, existem cinco disciplinas que podem estimular o debate e o estudo de tópicos ligados à infância. São elas: Linguística aplicada à língua materna, Didática, Linguística aplicada ao ensino da língua estrangeira e Teorias da educação e da aprendizagem. 
Consideram-se essas disciplinas como possíveis promotoras de discussão e estudos sobre a infância, pois as suas temáticas envolvem tópicos como o processo de aquisição da língua materna, as concepções de ensino e aprendizagem, a aquisição de línguas estrangeiras, aprendizagem de línguas e processo de ensino-aprendizagem escolar. Todos esses tópicos perpassam o tema da infância mesmo que esse não seja o seu enfoque.

De todas as disciplinas elencadas acima, somente uma disciplina seria passível de abordar o tema da infância especificamente no contexto do ensino de LI. Contudo, vale a pena ressaltar que esse curso ainda não se propõe a formar um profissional para o trabalho com a infância.

\section{A INFÂNCIA NOS CURRÍCULOS}

Os termos descritos e observados nas matrizes, ementários e PPCs dos cursos ora abordados foram separados e analisados um a um. Essa análise se deu para o entendimento do enfoque que poderia ser dado nas disciplinas quando fossem discutidos nas universidades, se de cunho pedagógico, ou se esses termos fariam parte de discussões sobre as etapas da infância (ver tabela 2).

Para essa análise, concorda-se com Tardif quando o autor expõe que " a pedagogia é o conjunto de meios empregados pelo professor para atingir seus objetivos no âmbito das interações educativas com os alunos." (2012, p.117, grifo do autor). Nessa perspectiva, ainda segundo o autor, a pedagogia está diretamente relacionada às tecnologias utilizadas para o desenvolvimento do seu trabalho no cotidiano da escola. No caso desta pesquisa, consideram-se discussões voltadas para uma perspectiva pedagógica os termos relacionados à metodologias e abordagens de ensino, estratégias para a aquisição de uma língua, materiais/espaços e forma de utilizá-los.

Todavia, para a formação do futuro professor faz-se necessário, além dos conhecimentos pedagógicos referentes ao ensino da língua em questão, o estudo da concepção de infância. Portanto, corrobora-se com Oliveira (2012) quando o autor considera a temporalidade da infância como os tempos vividos pela infância. Nessa perspectiva serão analisados os tópicos e as disciplinas que apresentam discussões que ampliem a visão sobre características, vivências e especificidades da infância que não estão diretamente ligadas às formas de se trabalhar com crianças na escola.

A partir dos documentos que os cursos de licenciatura em Letras (Inglês) apresentam em seus websites, apresenta-se, abaixo, uma tabela que exemplifica o enfoque dado nas disciplinas que apresentam termos relacionados à infância. Ressalta-se que os currículos E e F apresentam os termos analisados somente na disciplina de Literatura infantil-juvenil (E) e Literatura infantil- 
juvenil brasileira (F). Já o currículo $G$ não prevê disciplina com os termos infância, criança, crianças, infantojuvenil, infantil, anos iniciais ou séries iniciais em seu ementário.

TABELA 2. ANÁLISE DOS TERMOS CURRICULARES

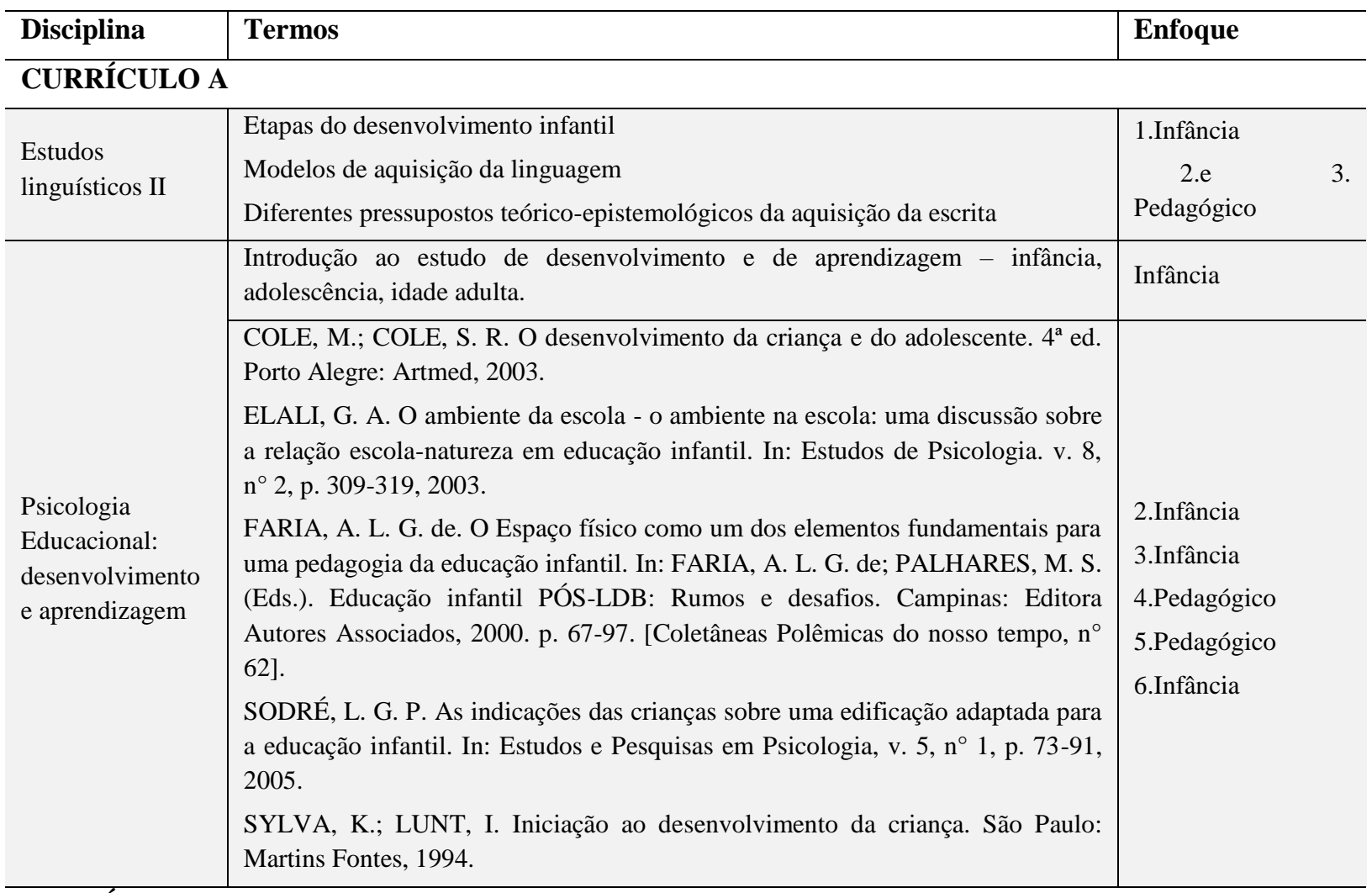

\section{CURRÍCULO B}

\begin{tabular}{|c|c|c|}
\hline $\begin{array}{l}\text { Metodologia do } \\
\text { ensino de língua } \\
\text { inglesa para } \\
\text { séries iniciais }\end{array}$ & $\begin{array}{l}\text { Ideias no ensino de língua inglesa para crianças de } 03 \text { a } 10 \text { anos, incluindo } \\
\text { canções, jogos, drama, contos de fadas, projetos, teatro e internet. Atividades } \\
\text { para sala de aula para ampliar o potencial de ensino com implicações } \\
\text { metodológicas resultantes de diferentes abordagens. }\end{array}$ & Pedagógico \\
\hline Neurociência & $\begin{array}{l}\text { Abordagens na neurociência sobre o desenvolvimento da criança, do jovem e do } \\
\text { adulto. }\end{array}$ & Infância \\
\hline $\begin{array}{l}\text { Atividade física } \\
\text { como qualidade } \\
\text { de vida na } \\
\text { infância } \\
\text { adolescência }\end{array}$ & $\begin{array}{l}\text { Adaptações orgânicas induzidas pelo exercício físico no aparelho locomotor e } \\
\text { sistemas respiratório-cardiovascular em crianças; manutenção do peso corporal } \\
\text { através do exercício físico em crianças e adolescentes; relação entre saúde x } \\
\text { exercício físico x criança. }\end{array}$ & Infância \\
\hline
\end{tabular}

\section{CURRÍCULO C}

Literatura infantojuvenil
1.Estudo do conceito de literaturas infantil-juvenil e caracterização deste tipo de texto.

ALBERGARIA, Lino. Do folhetim à literatura infantil: leitor, memória e identidade. Belo Horizonte: Lê, 1997.

COELHO, Nelly Novaes. Panorama histórico da literatura infantojuvenil. $4^{\mathrm{a}}$ ed. São Paulo: Ática, 1991.

FOUCAMBERT, Jean. A criança, o professor e a leitura. Porto Alegre: Artes médicas, 1998.

LAJOLO, Marisa; ZILBERMAN, Regina. Literatura infantil brasileira: história e histórias. São Paulo: Ática 1984.

PERROTI, Edmir. O texto sedutor da literatura infantil. São Paulo: Ícone,
Pedagógico

2.Infância

3.Pedagógico

4.Pedagógico

5.Pedagógico

6.Pedagógico

7.Infância

8.Pedagógico

9.Pedagógico 


\begin{tabular}{|c|c|c|}
\hline & $\begin{array}{l}1986 . \\
\text { ÁRIES, Philippe. História social da criança e da família. Rio de Janeiro: } \\
\text { Guanabara, 1981. } \\
\text { COELHO, Nelly Novaes. Literatura infantil: teoria - análise - prática. São } \\
\text { Paulo: Ática, 1991. } \\
\text { ZILBERMAN, Regina; MAGALHÃES, Ligia Cadermartori. Literatura } \\
\text { infantil; autoritarismo e emancipação. São Paulo: Ática, 1984. } \\
\text { ZILBERMAN, Regina. A literatura infantil na escola. São Paulo: Global, } \\
\text { 1982. }\end{array}$ & 10.Pedagógico \\
\hline $\begin{array}{l}\text { Metodologia do } \\
\text { ensino da língua } \\
\text { portuguesa }\end{array}$ & $\begin{array}{l}\text { CURTO, Luís Maruny. Escrever e ler: como as crianças aprendem e como o } \\
\text { professor pode ensiná-las a ler e escrever. Porto Alegre: Artes Médicas Sul, } \\
2000, v .1 \text { e } 2 \text {. }\end{array}$ & Pedagógico \\
\hline \multicolumn{3}{|l|}{ CURRÍCULO D } \\
\hline \multirow[b]{2}{*}{$\begin{array}{l}\text { Literatura } \\
\text { infantojuvenil }\end{array}$} & $\begin{array}{l}\text { 1.Estudo do conceito de literaturas infantil-juvenil e caracterização deste tipo de } \\
\text { texto. }\end{array}$ & Pedagógico \\
\hline & 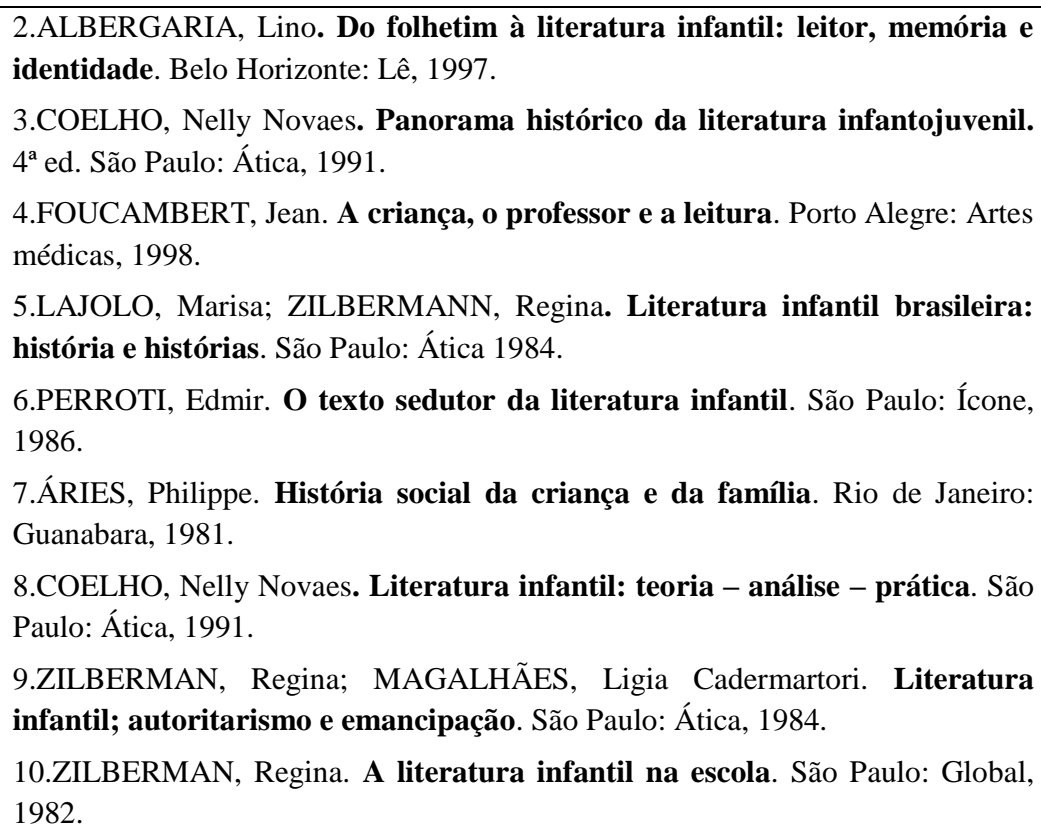 & $\begin{array}{l}\text { 2.Infância } \\
\text { 3.Pedagógico } \\
\text { 4.Pedagógico } \\
\text { 5.Pedagógico } \\
\text { 6.Pedagógico } \\
\text { 7.Infância } \\
\text { 8.Pedagógico } \\
\text { 9.Pedagógico } \\
\text { 10.Pedagógico }\end{array}$ \\
\hline
\end{tabular}

Fonte: pesquisadoras

Os termos classificados na tabela 2 apresentam um total de 11 temáticas/obras voltadas para discussões sobre a infância e 23 temáticas/obras para possíveis discussões de cunho pedagógico sobre o ensino de línguas para crianças. Esses dados demonstram que, em se tratando de discussões acerca da infância nos cursos de Letras, quando elas acontecem, a sua grande maioria retrata as formas de atuação docente com as crianças. Contudo, cabe ainda afirmar que, dentre os termos classificados como possíveis discussões acerca da infância, nem todos abordam somente tópicos referentes à temporalidade da infância, mas pressupõe-se que também abordarão discussões acerca das ações que os acadêmicos enfrentarão quando estiverem trabalhando com essa temporalidade humana. 


\section{CONSIDERAÇÕES FINAIS}

O presente estudo objetivou identificar nas propostas curriculares dos cursos de Letras com habilitação em LI a intencionalidade de uma formação docente para a infância. O que se pode considerar acerca das análises realizadas das matrizes, dos ementários e, Projetos Pedagógicos dos Cursos, é a fragilidade que existe nos currículos quando se observa a existência de discussões sobre a infância nas disciplinas de formação do profissional de LE. O termo infância aparece em cinco dos sete ementários dos currículos analisados. Contudo, somente em três disciplinas há a ocorrência de termos ligados à infância no currículo que forma professores de LI. Soma-se a isso ainda a questão de que uma dessas disciplinas faz parte das disciplinas opcionais do curso, ou seja, nem todos os acadêmicos a cursarão. As outras ocorrências de termos relacionados à infância ocorrem somente quando se trata do ensino da LP, o que pouco contribui para a formação do futuro professor de inglês.

Quando se observam discussões sobre a infância nas disciplinas listadas na tabela 2, verifica-se que elas estão mais voltadas para discussões pedagógicas em lugar das preocupações com os tempos da infância ou mesmo da compreensão do que vem a ser infância. Com isso, não se permite o transpor das práticas, conteúdos e métodos, ou seja, não se permite "entender o que ela [a infância] nos diz sobre as possibilidades de sermos humanos.” (ARROYO, 2011, p.45).

Para finalizar, considera-se pertinente afirmar que há uma carência de amparo legal no que consta a oferta de LI para crianças. Possivelmente, com essa contrapartida legal, seria possível haver uma mudança significativa nos currículos de Letras, de maneira que eles contemplassem uma formação que considerasse discutir a infância em seus currículos. 


\section{REFERÊNCIAS}

ARROYO, Miguel G. Oficio de mestre: imagens e auto-imagens. 13. ed. RJ:Vozes, 2011.

CONSELHO NACIONAL DE EDUCAÇÃO. Estabelece diretrizes para a obtenção de uma nova habilitação pelos portadores de Diploma de Licenciatura em Letras. Resolução CNE/CP 01, 18 mar. 2011. Diário Oficial da União, Brasília, 22 de março de 2011. Seção 1, p. 14-15. Disp.: <http://portal.mec.gov.br/index.php?option=com docman\&view=download\&alias=7711-rcp001-11-pdf\&category slug=marco-2011-pdf\&Itemid=30192 > . Acesso em: 5 março 2016.

Institui a duração e a carga horária dos cursos de licenciatura, de graduação plena, de formação de professores da Educação Básica em nível superior. Resolução CNE/CP 02, 19 fev. 2002. Diário Oficial da União, Brasília, 4 mar. 2002. Seção 1, p. 9. Disp.: < http://portal.mec.gov.br/cne/arquivos/pdf/CP022002.pdf >. Acesso em: 5 março 2016.

GATTI, Bernadete A.; BARRETO, Elba S. Sá (Coord.). Professores do Brasil: impasses e desafios. Brasília: UNESCO, 2009.

LIMA, Gislaine P.; QUEVEDO-CAMARGO, Gladys. Breve trajetória da língua inglesa e do lívro didático de inglês no Brasil. In: Seminário de Pesquisa em Ciências Humanas, 7., 2008, Londrina. Anais... Londrina : Eduel, 2008. p. 01-07. Disp.: <http://www.uel.br/eventos/sepech/sepech08/arqtxt/resumos-anais/GislainePLima.pdf>. Acesso: 08 jan. 2017.

OLIVEIRA, Cristiane E.A. Oliveira. Cotidiano escolar da Educação Infantil: Temporalidades de crianças. In: ENDIPE, 16, 2012, Campinas. Anais ... São Paulo: Junqueira\&Marin Editores, v. 3, p. 550-561.

PIMENTEL, Alessandra. O método da análise documental: seu uso numa pesquisa historiográfica Cadernos de Pesquisa, São Paulo, n. 114, p. 179-195, nov. 2001. Disp.: <http://www.scielo.br/scielo.php?script=sci_arttext\&pid=

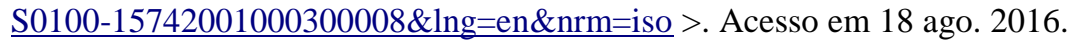

RAMALHO, Betania L.; NUÑEZ, Isauro B.; GAUTHIER, Clermont. Formar o professor, profissionalizar o ensino: perspectivas e desafios. 2. ed. Porto Alegre: Sulina, 2004.

ROCHA, Cláudia H. Provisões para ensinar Le no ensino fundamental de $\mathbf{1}^{\mathbf{a}}$ a $\mathbf{4}^{\mathbf{a}}$ séries: dos parâmetros oficiais e objetivos dos agentes. Dissertação (Mestre em Linguística Aplicada) - Instituto de Estudos da Linguagem, Universidade Estadual de Campinas, Campinas, SP. 2006.

SANTOS, Alfredo S. Ribas; ZÉGGIO, Maria T.. Da vocação sacerdotal à formação profissional: reflexões sobre as diretrizes curriculares para formação de professores da educação básica. O caso UNINOVE. In: Dialogia: Centro Universitário Nove de Julho. Departamento de Educação. São Paulo: Uninove, v. 1, p.159-168, out. 2002.

SANTOS, Leandra I.S.. Crenças acerca da inclusão de língua inglesa nas séries iniciais: quanto antes melhor? $230 f$. Dissertação (Mestrado em Estudos Linguísticos) - Instituto de Linguagem, Universidade Federal de Mato Grosso, Cuiabá, MT, 2005.

; BENEDETTI, Ana M. Professor de língua estrangeira para crianças: conhecimentos teórico-metodológicos desejados. Trabalhos em Linguística Aplicada, Campinas, vol. 48, n. 2. p. 333-351, jul./dez. 2009.

SPADA, Nina. Linguística Aplicada ao Ensino de Língua Estrangeira: uma entrevista com Nina Spada. ReVELRevista Virtual de Estudos da Linguagem, vol. 2, n. 2, 2004. Disp.: < http://www.revel.inf.br/files/entrevistas/ revel_2_entrevista_nina_spada.pdf > . Acesso em: 12 dez. 2015. Trad.: Gabriel de Ávila Othero.

TARDIF, Maurice. Saberes docentes e a formação profissional. 14.ed. Petrópolis, RJ: Vozes, 2012.

UNIVERSIDADE COMUNITÁRIA DA REGIÃO DE CHAPECÓ. Departamento de Letras. O curso. Disp.: <https:// www.unochapeco.edu.br/letras/o-curso/perfil-do-egresso\#menu-sobre-curso >. Acesso em: 10 jan. 2016.

Departamento de Letras. Síntese do PPC. Disp.: < https://www.unochapeco.edu.br/letras/o-curso/sinteseppc\#menu-sobre-curso >. Acesso em: 10 jan. 2016.

UNIVERSIDADE DA REGIÃO DE JOINVILLE. Departamento de Letras. Áreas de atuação. Disp.: <http://www. univille.edu.br/pt-BR/departamentos/letras/index/596694 >. Acesso em: 10 jan. 2016.

Departamento de Letras. Matriz curricular. Disp.: <http://univille.edu.br/community/novoportal/VirtualDisk. html? action=readFile\&file=Letras_2015.pdf\&current=/Departamentos/0matrizes/pasta2 >. Acesso em: 10 jan. 2016.

Revista Teias v. 18, n. 50, 2017 (Jul./Set.): Conversas sobre formação de professores, práticas e currículos 
UNIVERSIDADE DE BLUMENAU. Departamento de Letras. Apresentação do curso de graduação em Letras: Português/Inglês. Disp.: < http://www.furb.br/web/1788/cursos/graduacao/cursos/letras/apresentacao >. Acesso em: 10 jan. 2016.

Departamento de Letras. Currículo do curso de graduação em Letras: Português/Inglês. Disp.: <http:// www.furb.br/web/1788/cursos/graduacao/cursos/letras/apresentacao . Acesso em: 10 janeiro 2016.

UNIVERSIDADE DO ALTO VALE DO RIO DO PEIXE. Departamento de Letras Trilíngue. Apresentação do curso de graduação em Letras Trilíngue: Português/Inglês/Espanhol. Disp.: <http://www.uniarp.edu.br/home/ensino/ graduacao/letras-trilingue/>. Acesso em: 10 janeiro 2016.

Departamento de Letras Trilíngue. Ementário do curso de graduação em Letras Trilíngue: Português/Inglês/Espanhol. Disp.: < http://extranet.uniarp.edu.br/letras/Ementas/Forms/EMENTAS.aspx >. Acesso em: 10 janeiro 2016.

UNIVERSIDADE DO CONTESTADO. Departamento de Letras. Apresentação do curso de graduação em Letras: Português/Inglês. Disp.: < http://www.unc.br/course/letras-portugues-ingles-e-espanhol/ >. Acesso em: 10 jan. 2016.

Departamento de Letras. Ementas do curso de graduação em Letras: Português/Inglês. Disp.: <http://www. unc.br/ensino/ementas_grad/ementa-letras-portugues-ingles-licenciatura-2012.pdf>. Acesso em: 10 jan. 2016.

UNIVERSIDADE DO EXTREMO SUL CATARINENSE. Departamento de Letras Português. Apresentação do curso de graduação em Letras Português. Disp.: < http://www.unesc.net/portal/capa/index/55>. Acesso em: 10 jan. 2016.

UNIVERSIDADE DO OESTE DE SANTA CATARINA. Departamento de Letras Português. Apresentação do curso de graduação em Letras Português. Disp.: <http://www.unoesc.edu.br/cursos/graduacao/letras-lingua\%20portuguesa/ apresentacao/1044/\%20300/matriz >. Acesso em: 10 jan. 2016.

UNIVERSIDADE DO PLANALTO CATARINENSE. Departamento de Letras. Apresentação. Disp.: <http://www. uniplaclages.edu.br/graduacao/apresentacao/27-letras-lingua-portuguesalingua-inglesa >. Acesso em: 10 jan. 2016.

Departamento de Letras. Ementas. Disponível em: <http://www.uniplaclages.edu.br/graduacao/grade_ disciplinas/27-letras-lingua-portuguesalingua-inglesa/84-letras-portuguesingles-ead-lc >. Acesso em: 10 jan. 2016.

UNIVERSIDADE DO SUL DE SANTA CATARINA. Departamento de Letras Português. Apresentação do curso de graduação em Letras Português. Disp.: < http://www.unisul.br/wps/portal/home/ensino/graduacao/letras-linguaportuguesa/\#?unidade=21>. Acesso em: 10 jan. 2016.

UNIVERSIDADE DO VALE DO ITAJAÍ. Departamento de Letras Português. Apresentação do curso de graduação em Letras Português. Disp.: 〈http://www.univali.br/ensino/nucleo-das-licenciaturas/letras-habilitacao-em-linguaportuguesa-e-respectivas-literaturas/Paginas/default.aspx\#>. Acesso em: 10 jan. 2016.

UNIVERSIDADE DE BRASÍLIA. Programa de pós-graduação em linguística aplicada. Helb: História do ensino de línguas do Brasil. Disp.: <http://www.helb.org.br/index.php?option=com_content\&view=article\&id=32:1db-de-1961

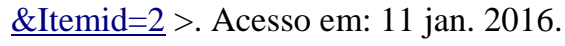

UNIVERSIDADE FERDERAL DE SANTA CATARINA. Departamento de Língua e Literatura Estrangeiras. Apresentação do curso de graduação em Inglês. Disp.: < http://www.lle.cce.ufsc.br/cursos/ingles/ >. Acesso em: 10 jan. 2016.

. Departamento de Língua e Literatura Estrangeiras. Programa das disciplinas do curso de graduação em Inglês. Disp.: <http://www.lle.cce.ufsc.br/cursos/ingles/>. Acesso em: 10 jan. 2016.

UNIVERSIDADE FEDERAL DA FRONTEIRA SUL. Departamento de Letras Português/Espanhol. Apresentação do curso de graduação em Letras: Português/ Espanhol. Disp.: <http://www.uffs.edu.br/index.php?option=com_conten $\underline{\mathrm{t} \& \text { view }=\text { article } \& \mathrm{id}=1158 \& \text { Itemid }=1737}>$. Acesso em: 10 jan. 2016. 


\section{RESUMO}

Com a globalização e a internacionalização, faz-se cada vez mais presente a Língua Inglesa no cotidiano das crianças brasileiras, o que atualmente se faz também em escolas públicas em algumas cidades do Brasil. Desse modo, este artigo objetiva identificar nas propostas curriculares dos cursos de Letras, com habilitação em Língua Inglesa, a intencionalidade de uma formação docente voltada para a infância. Esta pesquisa é de cunho documental, envolvendo a análise das matrizes curriculares e ementários de cursos de Letras presenciais. Percebe-se com esta pesquisa, o pouco enfoque dado para a formação em Língua Inglesa nos cursos que ofertam mais de uma habilitação, além da ausência de discussões que envolvem o ensino de inglês para crianças.

Palavras-chave: Currículo . Licenciatura em Letras . Inglês para crianças.

\section{THE CURRICULUM OF ENGLISH LETTERS LICENCIATE: PROFESSIONAL TRAINING TO WORK WITH CHILDREN \\ ABSTRACT:}

With globalization and internationalization, the English Language is increasingly present in the everyday life of Brazilian children, which is currently being done in public schools in some cities in Brazil. Thus, this article aims to identify, in the course proposals of the English letters licentiate academic courses, the intent of a teacher's formation to childhood. This research is a documental research, involving the analysis of the course curriculum and syllabus of the Licentiate courses with class attendance which form the academic to the work with English language. It was noticed, by doing this research, the little emphasis given on the formation of letters licenciate in English in the courses that form teachers to work with more than one language, besides the absence of discussions which involve teaching English to children.

Keywords: Curriculum . Letters licentiate. English for chidren.

\section{CURSOS DE LICENCIATURA EN LENGUA INGLESA: FORMACIÓN PARA EL TRABAJO CON NIÑOS RESUMEN}

Con la globalización y la internacionalización, se hace cada vez más presente la Lengua Inglesa en el cotidiano de los niños brasileños, lo que actualmente se hace temblando en escuelas públicas en algunas ciudades de Brasil. De este modo, este artículo objetiva identificar en las propuestas curriculares de los cursos de Letras, con habilitación en Lengua Inglesa, la intencionalidad de una formación docente orientada hacia la infancia. Esta investigación es de cuño documental, involucrando el análisis de las matrices curriculares y eminentes de cursos de Letras presenciales. Se percibe con esta investigación, el poco enfoque dado para la formación en Lengua Inglesa en los cursos que ofrecen más de una habilitación, además de la usencia de discusiones que involucran la enseñanza de inglés para niños.

Palabras clave: Currículo. Licenciatura en Letras. Inglés para niños. 